
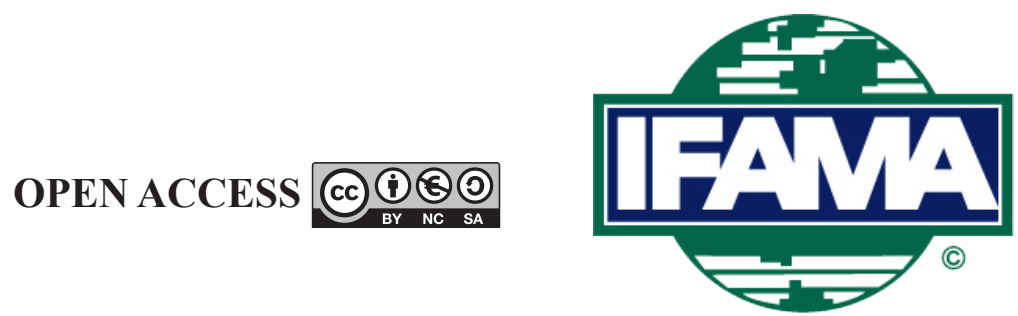

International Food and Agribusiness Management Review

Volume 24, Issue 5, 2021; DOI: 10.22434/IFAMR2020.0159

Received: 13 September 2020 / Accepted: 16 February 2021

\title{
Building consumer trust in online food marketplaces: the role of WeChat marketing
}

RESEARCH ARTICLE

\author{
Si Tan ${ }^{\mathrm{a}}$ and Weiping Chen ${ }^{\circledR b}$ \\ ${ }^{a}$ Lecturer, School of Economics, Beijing Technology and Business University, \\ No. 33 Fucheng Road, Haidian District, Beijing, 100048, China P.R. \\ ${ }^{b}$ Professor, School of Agriculture Economics and Rural Development, Renmin University of China, \\ No. 59 Zhongguancun Street, Haidian District, Beijing, 100872, China P.R.
}

\begin{abstract}
Consumer trust receives high attention in food marketplaces, however, little research focuses on how to build consumer trust in the online context. Drawing on signaling theory and presence theory, this paper proposes a comprehensive framework with which to explain the influence mechanism of WeChat food marketing on consumer trust. Utilizing data from 672 consumers in China's WeChat food marketplaces, this study conducted a partial least squares structural equation modeling analysis. The findings indicate that food seller's content behavior and interactive behavior on WeChat positively affect consumer trust through the mediating effect of consumer's perceived information quality and presence. And consumer trust can enhance consumer loyalty. This study extends the research on consumer trust in online food marketplaces. It also provides certain theoretical guidance for food marketers to make better use of WeChat for trust building.
\end{abstract}

Keywords: consumer trust, WeChat marketing, information quality, presence, online food marketplaces JEL code: Q13, M31, D12

\footnotetext{
(1)Corresponding author: chenweipingruc@ruc.edu.cn; chenwpruc@126.com
} 


\section{Introduction}

Over the past two decades, consumer trust has received increasing attention in food marketplaces. Evidence has shown that consumer trust can affect outcomes such as perceived risk (Siegrist et al., 2008), satisfaction, and loyalty (Herrera and Blanco, 2011). Food sellers thus work to build consumer trust, with the belief that doing so will increase their success. Researchers have begun to investigate how to build trust in food marketplaces. For example, prior research has identified three main trust building mechanism: informational mechanism (e.g. Tan and Chen, 2018), relational mechanism (e.g. Poppe and Kjærnes, 2003), and institutional mechanism (e.g. De Jonge et al., 2008). However, prior studies have focused mainly on offline food marketplaces (e.g. supermarket) (e.g. Chen, 2013), only limited research pays attention to online trust building.

Although there are some similarities between online trust and offline trust, such as both of them have the same key elements (e.g. willingness to accept vulnerability and positive expectations of trustworthiness) (Beldad et al., 2010), differences are also inherent between them. Shankar et al. (2002) identified that they are different in the trust objects. Specifically, the object of offline trust is typically a human or an entity (organization) in an offline context, while the objects of online trust are not only a person or an organization but also the technology (primarily the Internet) in an online context. Moreover, the obvious differences between online and offline channels hinder simple applications of offline trust building strategies to online context. For example, offline relational partners are in geographic proximity to each other, thereby they can communicate face-to-face and know the identity of potential partners. Although online communication is not limited by time and space, most online relational partners cannot communicate face-to-face and have little knowledge of each other's true identity. Moreover, many online relational partners act as followers in the unilateral relationship, which is not the same as offline relational partners because they have social pressure to reciprocate (Kozlenkova et al., 2017). Furthermore, offline consumers can touch the product, while online consumers only perceive the product depend on online information accessed from marketers or other consumers. Most of these differences increase the risk caused by the opportunistic behavior of online sellers, which may result in differences in trust building strategies between online and offline.

From a practice perspective, shopping food online continues to increase. For example, China's online retailing sales of agricultural products reached 397.5 billion yuan in 2019, a year-on-year increase of 27\% (Ministry of Commerce of the People's Republic of China, 2020). Nevertheless, some food firms still failed in their online strategies, because consumers are worried about the security or privacy in the transaction (Hajli et al., 2017). Given that trust can reduce consumers' anxiety and uncertainty and increase firms' performance (Kim and Park, 2013), practitioners are eager to know how to effectively build online consumer trust. However, there is a paucity of theoretical guidance on trust building online for food sellers.

This study aims to investigate consumer trust building in online food marketplaces. We concentrate on the context of WeChat food marketing in China. WeChat is the social media with the largest user base in China. It offers various information exchange platforms such as Official Accounts, Moments, and Mini Programs, and supports one-to-one or one-to-many communication with multiple forms (e.g. pictures, videos, voices). It has gradually become one of the most popular online trading platforms in China. Thus, it is particularly appropriate to conduct such research in China at this time. Given that seller behavior plays a key role in explaining consumer food trust (Sillence et al., 2016), this study focuses on discussing how food seller's WeChat marketing behavior affects consumer trust. Drawing on signaling theory and presence theory, this study applied a partial least squares structural equation modeling (PLS-SEM) to analyze 672 consumer samples in China's WeChat food marketplaces.

This paper is organized as follows. After the introduction, it provides theoretical background related to consumer food trust and elaborates on research hypotheses. Subsequently, it explicates the empirical methodology and research results in detail. Finally, it discusses findings and concludes with the implications, limitations, and future directions. 


\section{Theoretical background and hypotheses development}

\subsection{Theoretical background}

Trust, an essential construct in relationship marketing (Zhang et al., 2016), receives increasing attention in food marketplaces recently. It is conceptualized as the confidence in an exchange partner's integrity, benevolence, and ability (Gefen et al., 2003). Prior studies have identified that trust is a key predictor of performance (e.g. Lees et al., 2020; Pentina et al., 2013). It can increase consumer loyalty (Park et al., 2017), satisfaction (Kim and Peterson, 2017), word-of-mouth (Wang et al., 2016), or reduce perceived risk (Siegrist et al., 2008), thereby enhance performance. Thus, marketers need to build consumer trust.

Food economy scholars have begun to investigate how to build consumer trust. Three major mechanisms have been found to interpret trust building in offline food marketplaces. The first, also the greatest concern, is the informational mechanism. This trust building mechanism emphasizes the influence of information (e.g. media reports or unsolicited messages) on trust (e.g. Tan and Chen, 2018). The second is the relational mechanism, which focuses on social and interpersonal aspects (e.g. Poppe and Kjærnes, 2003). The third is the institutional mechanism (e.g. De Jonge et al., 2008). The identified institutional-based antecedents of food trust include the system of food provision, food regulators, experts, informers, watchdogs, etc.

However, there are many changes in online food marketplaces, which may impede simple applications of offline trust building strategies to online channels. In online marketplaces, computer-mediated communication technologies have changed the elements of time, space, and connectivity in the business environment, as well as the behavior of business subjects. For example, consumer behavior becomes more mobile, social, and specialized. Firms aim to create consumer values and provide consumers with a comprehensive dataservice-product package (Chen et al., 2020). In the digital business environment, the purpose of food seller's marketing behavior is no longer just the transaction, but also the establishment of consumer relationship or other purposes. However, these changes make it difficult to communicate face-to-face online, and consumers cannot directly contact products, thereby increasing the risk caused by the opportunistic behavior of online sellers. Overall, these changes puzzle practitioners about how to build consumer food trust online.

A few researchers have begun to try to explain consumer trust in traditional food e-commerce environments (e.g. Taobao) (Yue et al., 2017). These studies mostly provide insights into explaining the information mechanism of consumer trust building. The major theoretical perspective is the signaling theory. Signaling theory is derived from the study of information asymmetry between two parties (Spence, 1973). If one party lacks the information possessed by the other party, this party will make decisions based on the signals sent by the other party. The essence of signaling theory is that signalers are insiders (e.g. organizations) who get information that is not available to outsiders (e.g. individuals) (Connelly et al., 2011). Researchers often use signaling theory to explain how risk-reducing signals affect consumer relationships (Oghazi et al., 2018).

Based on signaling theory, in WeChat food marketplaces, marketers will send signals about products, services, or companies to consumers as comprehensively as possible. Consumers are often simultaneously affected by one or more risk-reducing signals, of which quality signals are the key factor affecting their attitudes and behaviors (Yue et al., 2017). Information quality involves the up-to-date, accurate, useful, and complete content offered by marketers (Kim and Park, 2013). If consumers have a high evaluation of information quality, they are more likely to trust product quality. Therefore, this article infers that WeChat food seller's marketing behavior can improve consumer's perceived information quality, thereby enhancing consumer trust.

Besides, information economy researchers believe that presence is a result of digital media communication that cannot be ignored. Recently presence theory received great attention in explaining consumer trust in digital marketing. Presence is the perception of intimacy or closeness to others. It reflects the quality of the media and the extent to which it improves psychological intimacy and physical proximity. Presence has two dimensions: social presence and telepresence. Social presence refers to the perception of psychologically 
present to communication partners (Gefen and Straub, 2004). Telepresence refers to the feeling of physical proximity to someone who is not on the scene. It is easier for people to establish rich interpersonal relationships in a close communication environment than in a distant communication environment (Ou et al., 2014). Thus, presence can lead to consumer trust in the digital environment ( $\mathrm{Lu}$ et al., 2016).

Drawing on presence theory, WeChat food sellers can use WeChat to transmit information quickly and vividly, giving an illusion that there is no intermediary between two communication parties (Fan et al., 2019). WeChat is a social media that provides a virtual social environment for communication. The social function of WeChat can provide communication partners with social interaction and acquire useful social knowledge and experience. Overall, WeChat communication can not only enhance consumers' sense of spatial proximity but also enhance their psychological intimacy. The feeling of presence may lead to their attitude and behavior changes. Therefore, this article infers that WeChat food seller's marketing behavior can enhance consumer's perceived presence, thereby enhancing consumer trust.

\subsection{Hypotheses development}

\section{- The impact of WeChat marketing behaviors on information quality and presence}

In line with previous studies (e.g. Tan and Chen, 2018), this study also concentrates on the role of seller behavior (e.g. WeChat marketing behavior) in building consumer trust. Chen and Tan (2019) identified two major WeChat marketing behaviors in community supported agriculture (transaction behavior and relational behavior) according to the marketing purpose. However, their classification does not include all possible types of activities, such as entertaining activities (e.g. posting a funny video). This study classified WeChat marketing behavior into the other two types in terms of the forms of WeChat communication, namely, content behavior and interactive behavior. Content behavior refers to information creation and disclosure on the WeChat platform. For example, posting a post related to product features or production process on Official Accounts or Moments. Interactive behavior refers to the use of WeChat to interact with consumers, such as handling consumer inquiries or after-sales issues online through private chat or group chat.

Both content behavior and interactive behavior are presented in the form of content. These visible or audible contents are key clues for consumers' decision-making, including internal clues directly related to product attributes and external clues that are not directly related to product attributes (e.g. reputation, third-party guarantees). Consumers receive a large amount of information from food e-commerce companies during information browsing or real-time interaction. And they assess the quality of information content during the entire information processing process. When marketers actively do content behaviors and interactive behaviors (e.g. providing rich and accurate product information, or responding to consumer inquiries timely and effectively), consumers are more inclined to get greater information quality perception. Therefore, this article argues that WeChat food seller's content behavior and interactive behavior can positively affect consumers' perceived information quality. Thus, the following research hypotheses are obtained:

H1a: WeChat food seller's content behavior has a positive impact on consumer's perceived information quality.

H1b: WeChat food seller's interactive behavior has a positive impact on consumer's perceived information quality.

As an instant messaging tool, WeChat allows communicators who are not in the same space or at the same time to communicate with rich content presentation methods (e.g. video, audio, or pictures). And it can achieve synchronous communication between communicators, making the communication similar to face-to-face communication. Generally, media richness influence presence. For example, a picture with a smiling face can easily give people a sense of contact with people (Gefen and Straub, 2004), or a video showing consumers a product can easily give people an immersive feeling. Also, content behaviors or interactive behaviors can 
increase consumers' perception of interactivity in specific language expressions. For instance, the language expression of questions will make consumers feel in contact with people. Moreover, interactive behaviors can realize synchronous communication, and shorten the physical and psychological distance between online food sellers and consumers. Therefore, this article proposes the following hypotheses:

H2a: WeChat food seller's content behavior has a positive impact on consumer's perceived presence.

H2b: WeChat food seller's interactive behavior has a positive impact on consumer's perceived presence.

\section{- The impacts of information quality and presence on consumer trust}

To reduce decision-making risks, consumers collect information through various channels in online transactions. Due to the information disadvantage, consumers' decision-making mostly relies on food sellers' public information. Research has shown that high-quality information content leads to consumer trust (Kim and Park, 2013). For example, Liao et al. (2006) pointed out that high-quality information offered on Internet platforms is more likely to prompt consumers to believe that sellers are trustworthy. Therefore, this study argues that when consumers perceive higher information quality, they are more likely to trust WeChat food marketers and their products.

Besides, an important feature of trust is the social context (Gefen and Straub, 2004). The trustee and the trustor can establish trust relationships through social interaction. When individuals feel warmth or intimacy during the interaction, they are more likely to trust the trustee (Ou et al., 2014). Existing studies have shown that presence can shorten the physical or psychological distance between consumers and sellers and help build consumer trust (Gefen and Straub, 2004). Therefore, this article argues that consumers' perceived presence has a positive effect on their trust in WeChat food marketing. This study thus proposes:

H3: Consumer perceived information quality has a positive impact on consumer trust.

H4: Consumer perceived presence has a positive impact on consumer trust.

\section{- The mediating role of information quality}

According to signaling theory, the product-related information disseminated by WeChat food marketers can increase consumers' awareness and understanding of products. When consumers' evaluation of information quality is higher, they are more likely to believe that food e-commerce is reliable (Yue et al., 2017). On the one hand, high-quality information requires food e-commerce companies to pay a higher cost, which may make consumers think that food e-commerce companies have a greater loss in opportunistic behavior. On the other hand, providing high-quality information always requires a certain degree of professionalism and capabilities, so that consumers may believe that food marketers are capable of providing high-quality products. Overall, consumers' perceived information quality can reduce their perception of uncertainty and risk, thereby promoting consumer trust. Thus, we believe that WeChat marketing behavior can affect consumer trust through the mediating effect of consumers' perceived information quality. Therefore, this study proposes the following hypotheses:

H5a: Consumer's perceived information quality plays a mediating role in the relationship between WeChat food seller's content behavior and consumer trust.

H5b: Consumer's perceived information quality plays a mediating role in the relationship between WeChat food seller's interactive behavior and consumer trust. 


\section{- The mediating role of presence}

According to presence theory, WeChat marketers' content behavior and interactive behavior can shorten the spatial distance and psychological distance between food marketers and consumers, so that consumers can get an on-site feel. When consumers have a higher sense of presence, they are more likely to believe that e-commerce will provide good products or services (Ou et al., 2014). Based on this, this article believes that food marketers' WeChat marketing behaviors can influence consumer trust through the mediating effect of consumer perceived presence. Therefore, this article proposes the following hypotheses:

H6a: Consumer's perceived presence plays a mediating role in the relationship between WeChat food seller's content behavior and consumer trust.

H6b: Consumer's perceived presence plays a mediating role in the relationship between WeChat food seller's interactive behavior and consumer trust.

\section{- The impact of trust on loyalty}

From the perspective of consumers, trust indicates that consumers confirm and recognize the merchant or its products. As the consumer trust level increases, consumers are more likely to make purchase decisions, word-of-mouth recommendations, or other loyal behaviors. Existing research also shows that trust positively affects loyalty (Ou et al., 2014). Therefore, this study chooses loyalty as the immediate outcome of trust and it will serve as a robust test of the proposed model. We thus propose:

H7: Consumer trust has a positive impact on consumer loyalty.

\section{- Control variables}

Studies have pointed out that trust disposition, purchase experience, seller reputation (Zahedi and Song, 2008), self-efficacy (Zhou, 2012), and tie strength (Bapna et al., 2017) have positive effects on consumer trust. Besides, purchase experience (Kandampully et al., 2015), seller reputation (Casalo et al., 2008), selfefficacy (Chen et al., 2015), tie strength (Wallace et al., 2017) have positive effects on consumer loyalty. Therefore, this study controlled the above variables to better test the theoretical model. Figure 1 shows the proposed framework.

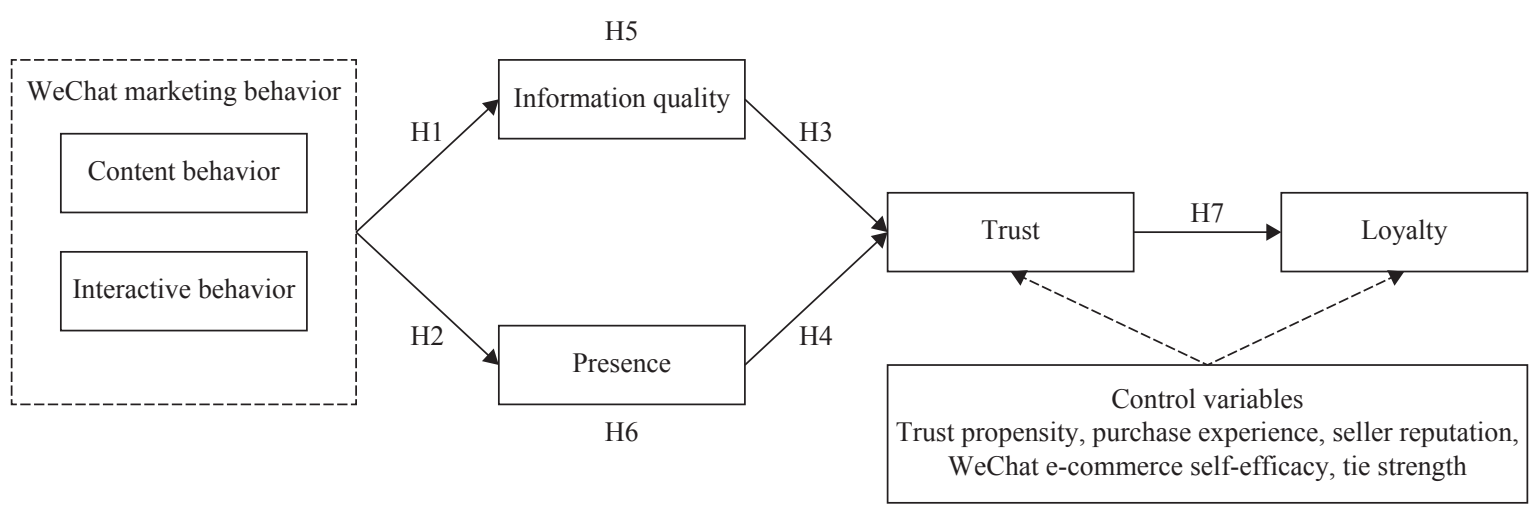

Figure 1. The proposed research framework. 


\section{Methods}

\subsection{Measures}

This study adapted the measured items from prior literature and modified them to reflect the context of WeChat food marketing. To ensure content validity, we first asked subject matter experts to review the questionnaire. Then we pretested the questionnaire among 15 target consumers before accepting it as the final version. No items were dropped from the pilot. Most of the items were on a seven-point scale, which is ranging from strongly disagree (1) through neutral (4) to strongly agree (7) (Gefen et al., 2003). The respondents were asked to choose the point (1-7) expressing how much they agree or disagree with each statement (item). Supplementary Table S1 lists the measurement items and their sources.

\subsection{Sample and data collection}

This study utilized the data collection service of Wenjuanxing (https://www.wjx.cn) to collect consumer data in WeChat food marketplaces. To improve data quality, this study did three things: setting up screening questions to locate the target population, gifting respondents to reduce the non-response bias, and screening samples through attention test questions and answering time control (the average answer time for each question should not less than 3 seconds). We collected data from December 21, 2019, to January 2, 2020, and got 683 samples. Excluding 11 samples with missing values or duplicate IP, we finally adopted 672 valid samples. Most of the consumers of WeChat food e-commerce are women (60.71\%), aged between 20 and $40(87.80 \%)$, with a bachelor degree or above $(84.53 \%)$ (Table 1$)$.

Table 1. Demographic distribution.

\begin{tabular}{llcc}
\hline Measure & Categories & Frequency & Percentage (\%) \\
\hline Gender & Male & 264 & 39.29 \\
& Female & 408 & 60.71 \\
\hline Age (year) & $<20$ & 15 & 2.23 \\
& $20-24$ & 127 & 18.90 \\
& $25-29$ & 179 & 26.64 \\
& $30-34$ & 206 & 30.65 \\
& $35-39$ & 78 & 11.61 \\
& $40-44$ & 25 & 3.72 \\
& $45-49$ & 26 & 3.87 \\
& $50-54$ & 12 & 1.79 \\
& $55-59$ & 1 & 0.15 \\
& $\geq 60$ & 3 & 0.45 \\
\hline \multirow{5}{*}{ Education } & Junior high school and below & 3 & 0.45 \\
& High school or technical secondary school & 27 & 4.02 \\
& Junior school & 74 & 11.01 \\
& College & 498 & 74.11 \\
& Postgraduate & 70 & 10.42 \\
\hline
\end{tabular}




\subsection{Data analysis}

The theoretical model above contains latent variables (e.g. trust, loyalty), which could not be measured directly but could only be measured indirectly through measured variables (Gefen et al., 2011). The structural equation model (SEM) has potential advantages over linear regression models to simultaneously handle both types of variables. SEM has two types: covariance- and variance-based SEM. This study selected variancebased SEM. It is the method if the hypothesized model contains composites. It first creates proxies as linear combinations of observed variables and then estimates the parameters using these proxies (Henseler et al., 2016). Among variance-based SEM methods, partial least squares (PLS) path modeling is most fully developed and widely used, such as Ou et al.'s (2014) and Lu et al.'s (2016) researches. We applied PLSSEM for three main reasons. First, PLS-SEM is more suitable for exploratory research (Gefen et al., 2011). This study focuses on consumer trust in WeChat food marketplaces, which is exploratory research where the relationships of the constructs have not been previously tested. Second, this study proposed a complex model with 11 latent variables and 37 observed variables, but PLS-SEM can estimate such a complex model very well. Third, consumer self-reported data does not meet the conditions of a normal distribution. PLS path modeling has less strict assumptions about the distribution of variables (Henseler et al., 2009), which is suitable for this research. A PLS-SEM consists of two sets of linear equations. One is the measurement models, which specify the relationship between the latent variables and their observed indicators. Another is the structural model, which specifies the relations between the latent variables (latent exogenous and endogenous variables) (Tang et al., 2015). The specific equations of the proposed model are presented in Appendix S1 of the Supplementary Material.

\section{Results}

\subsection{Measurement model}

This study evaluated the reflective measurement models by internal consistency reliability, convergent validity, and discriminant validity. First, Cronbach's $\alpha$ values of presence, trust, and loyalty are between 0.7 and 0.9 , indicating a high level of reliability. Cronbach's $\alpha$ values of content behavior, interactive behavior, and information quality are between 0.5 and 0.7 , showing medium level reliability (Hinton et al., 2004). Also, the construct reliability (CR) values of all latent variables are higher than the threshold value of 0.7 recommended by Fornell and Larcker (1981) (Table 2). Therefore, it can be considered that the measurement model in this paper has acceptable reliability. Second, all average variance extracted (AVE) values exceed the cut-off value of 0.5 by Fornell and Larcker (1981). Besides, most items have excellent outer loadings higher than 0.707, with five-item loadings (CB1, CB2, IQ3, PR1, and PR5) within the acceptable 0.450.70 range (Chin, 1998) (Table 2). The evaluation indicates that the measurement has a good convergence validity. Third, cross-loadings of an item's outer loading on the associated construct are greater than all of its loadings on other constructs (e.g. the cross-loadings) (Table 3). And all the reflective variables fulfill Fornell-Larcker's criterion because the square root of each AVE is greater than the correlations between the constructs with reflective items (Fornell and Larcker, 1981). Moreover, in all cases, the HTMT values are below the threshold of 0.90 (Henseler et al., 2015) (Table 4). These results confirm that discriminant validity exists in this study. Overall, the results indicate that the measurement model meets all the requirements. 
Table 2. Cross-loading, validity, and reliability. ${ }^{1}$

\begin{tabular}{|c|c|c|c|c|c|c|c|}
\hline Construct & Items & Mean & STD & $\begin{array}{l}\text { Outer } \\
\text { loadings }\end{array}$ & Cronbach's $\alpha$ & CR & AVE \\
\hline \multirow[t]{3}{*}{ Content behavior } & CB1 & 5.66 & 1.038 & 0.667 & 0.542 & 0.764 & 0.521 \\
\hline & $\mathrm{CB} 2$ & 4.81 & 1.338 & 0.703 & & & \\
\hline & CB3 & 4.96 & 1.203 & 0.788 & & & \\
\hline \multirow[t]{3}{*}{ Interactive behavior } & IB1 & 5.49 & 1.254 & 0.749 & 0.594 & 0.785 & 0.550 \\
\hline & IB2 & 5.52 & 1.137 & 0.707 & & & \\
\hline & IB3 & 5.43 & 1.195 & 0.767 & & & \\
\hline \multirow[t]{3}{*}{ Information quality } & IQ1 & 5.51 & 0.967 & 0.813 & 0.624 & 0.800 & 0.576 \\
\hline & IQ2 & 5.42 & 1.046 & 0.843 & & & \\
\hline & IQ3 & 5.58 & 1.129 & 0.597 & & & \\
\hline \multirow[t]{5}{*}{ Presence } & PR1 & 4.94 & 1.159 & 0.534 & 0.765 & 0.843 & 0.524 \\
\hline & PR2 & 4.82 & 1.309 & 0.786 & & & \\
\hline & PR3 & 4.72 & 1.357 & 0.815 & & & \\
\hline & PR4 & 4.73 & 1.432 & 0.796 & & & \\
\hline & PR5 & 5.07 & 1.203 & 0.649 & & & \\
\hline \multirow[t]{3}{*}{ Trust } & TR1 & 5.69 & 0.932 & 0.793 & 0.714 & 0.840 & 0.636 \\
\hline & TR2 & 5.42 & 1.065 & 0.794 & & & \\
\hline & TR3 & 5.73 & 1.008 & 0.805 & & & \\
\hline \multirow[t]{4}{*}{ Loyalty } & LO1 & 5.67 & 0.888 & 0.721 & 0.751 & 0.843 & 0.574 \\
\hline & $\mathrm{LO} 2$ & 5.74 & 1.02 & 0.710 & & & \\
\hline & LO3 & 5.36 & 1.171 & 0.797 & & & \\
\hline & $\mathrm{LO} 4$ & 5.33 & 1.169 & 0.799 & & & \\
\hline \multirow[t]{4}{*}{ Trust disposition } & TD1 & 4.82 & 1.265 & 0.772 & 0.830 & 0.885 & 0.658 \\
\hline & TD2 & 5.12 & 1.223 & 0.840 & & & \\
\hline & TD3 & 4.93 & 1.177 & 0.805 & & & \\
\hline & TD4 & 5.19 & 1.321 & 0.827 & & & \\
\hline Purchase experience & EX & 4.91 & 1.356 & 1.000 & 1.000 & 1.000 & 1.000 \\
\hline \multirow[t]{4}{*}{ Reputation } & RE1 & 4.71 & 1.223 & 0.734 & 0.785 & 0.861 & 0.609 \\
\hline & RE2 & 5.52 & 1.002 & 0.847 & & & \\
\hline & RE3 & 5.35 & 1.082 & 0.824 & & & \\
\hline & RE4 & 5.38 & 1.25 & 0.706 & & & \\
\hline \multirow[t]{3}{*}{ WeChat e-commerce self-efficacy } & SE1 & 6.05 & 0.904 & 0.757 & 0.680 & 0.824 & 0.610 \\
\hline & SE2 & 5.80 & 1.152 & 0.780 & & & \\
\hline & SE3 & 5.86 & 0.929 & 0.805 & & & \\
\hline \multirow[t]{4}{*}{ Tie strength } & TS1 & 4.83 & 1.295 & 0.746 & 0.849 & 0.899 & 0.690 \\
\hline & TS2 & 4.03 & 1.497 & 0.865 & & & \\
\hline & TS3 & 4.24 & 1.589 & 0.854 & & & \\
\hline & TS4 & 4.23 & 1.523 & 0.852 & & & \\
\hline
\end{tabular}

${ }^{1} \mathrm{AVE}=$ average variance extracted; $\mathrm{CR}=$ construct reliability; STD = standard deviation. 
Table 3. Loadings and cross-loadings. ${ }^{1}$

\begin{tabular}{|c|c|c|c|c|c|c|c|c|c|c|c|}
\hline Items & CB & IB & IQ & PR & TR & LO & TD & EX & RE & SE & TS \\
\hline CB1 & 0.667 & 0.353 & 0.323 & 0.281 & 0.323 & 0.322 & 0.143 & 0.155 & 0.234 & 0.356 & 0.184 \\
\hline CB2 & 0.703 & 0.210 & 0.160 & 0.310 & 0.211 & 0.207 & 0.182 & 0.114 & 0.248 & 0.198 & 0.225 \\
\hline CB3 & 0.788 & 0.318 & 0.279 & 0.393 & 0.245 & 0.276 & 0.201 & 0.163 & 0.305 & 0.228 & 0.326 \\
\hline IB1 & 0.255 & 0.749 & 0.379 & 0.323 & 0.343 & 0.392 & 0.153 & 0.203 & 0.323 & 0.333 & 0.259 \\
\hline IB2 & 0.334 & 0.707 & 0.321 & 0.311 & 0.402 & 0.394 & 0.133 & 0.258 & 0.346 & 0.346 & 0.281 \\
\hline IB3 & 0.335 & 0.767 & 0.416 & 0.410 & 0.419 & 0.397 & 0.096 & 0.288 & 0.307 & 0.319 & 0.316 \\
\hline IQ1 & 0.238 & 0.340 & 0.813 & 0.239 & 0.477 & 0.430 & 0.206 & 0.249 & 0.336 & 0.335 & 0.265 \\
\hline IQ2 & 0.292 & 0.456 & 0.843 & 0.337 & 0.525 & 0.453 & 0.226 & 0.306 & 0.362 & 0.334 & 0.263 \\
\hline IQ3 & 0.305 & 0.349 & 0.597 & 0.322 & 0.280 & 0.388 & 0.242 & 0.261 & 0.313 & 0.338 & 0.278 \\
\hline PR1 & 0.282 & 0.252 & 0.207 & 0.534 & 0.254 & 0.219 & 0.164 & 0.055 & 0.192 & 0.234 & 0.216 \\
\hline PR2 & 0.355 & 0.367 & 0.281 & 0.786 & 0.285 & 0.376 & 0.199 & 0.272 & 0.371 & 0.252 & 0.396 \\
\hline PR3 & 0.403 & 0.370 & 0.332 & 0.815 & 0.337 & 0.401 & 0.221 & 0.261 & 0.369 & 0.289 & 0.386 \\
\hline PR4 & 0.361 & 0.401 & 0.302 & 0.796 & 0.381 & 0.401 & 0.215 & 0.273 & 0.367 & 0.196 & 0.422 \\
\hline PR5 & 0.241 & 0.305 & 0.280 & 0.649 & 0.337 & 0.338 & 0.260 & 0.192 & 0.320 & 0.230 & 0.387 \\
\hline TR1 & 0.306 & 0.408 & 0.510 & 0.359 & 0.793 & 0.545 & 0.236 & 0.244 & 0.438 & 0.395 & 0.303 \\
\hline TR2 & 0.290 & 0.437 & 0.420 & 0.380 & 0.794 & 0.486 & 0.207 & 0.287 & 0.442 & 0.332 & 0.274 \\
\hline TR3 & 0.267 & 0.408 & 0.449 & 0.322 & 0.805 & 0.493 & 0.211 & 0.242 & 0.419 & 0.361 & 0.248 \\
\hline LO1 & 0.253 & 0.394 & 0.457 & 0.352 & 0.506 & 0.721 & 0.197 & 0.341 & 0.420 & 0.452 & 0.314 \\
\hline $\mathrm{LO} 2$ & 0.288 & 0.419 & 0.472 & 0.323 & 0.519 & 0.710 & 0.238 & 0.319 & 0.438 & 0.373 & 0.279 \\
\hline LO3 & 0.307 & 0.365 & 0.387 & 0.399 & 0.441 & 0.797 & 0.239 & 0.293 & 0.400 & 0.362 & 0.401 \\
\hline LO4 & 0.293 & 0.423 & 0.367 & 0.401 & 0.464 & 0.799 & 0.226 & 0.315 & 0.441 & 0.378 & 0.422 \\
\hline TD1 & 0.137 & 0.036 & 0.152 & 0.182 & 0.138 & 0.133 & 0.772 & -0.017 & 0.109 & 0.085 & 0.091 \\
\hline TD2 & 0.197 & 0.191 & 0.290 & 0.250 & 0.257 & 0.263 & 0.840 & 0.103 & 0.177 & 0.188 & 0.160 \\
\hline TD3 & 0.240 & 0.149 & 0.214 & 0.276 & 0.226 & 0.248 & 0.805 & 0.061 & 0.184 & 0.163 & 0.230 \\
\hline TD4 & 0.197 & 0.129 & 0.254 & 0.224 & 0.235 & 0.278 & 0.827 & 0.122 & 0.186 & 0.205 & 0.171 \\
\hline EX & 0.203 & 0.338 & 0.358 & 0.303 & 0.323 & 0.420 & 0.095 & 1.000 & 0.366 & 0.217 & 0.372 \\
\hline RE1 & 0.317 & 0.253 & 0.253 & 0.380 & 0.312 & 0.349 & 0.137 & 0.215 & 0.734 & 0.235 & 0.411 \\
\hline RE2 & 0.285 & 0.356 & 0.414 & 0.350 & 0.502 & 0.473 & 0.180 & 0.294 & 0.847 & 0.310 & 0.368 \\
\hline RE3 & 0.264 & 0.355 & 0.403 & 0.373 & 0.486 & 0.475 & 0.195 & 0.277 & 0.824 & 0.307 & 0.399 \\
\hline RE4 & 0.296 & 0.382 & 0.281 & 0.329 & 0.359 & 0.441 & 0.128 & 0.353 & 0.706 & 0.309 & 0.416 \\
\hline SE1 & 0.280 & 0.292 & 0.334 & 0.226 & 0.369 & 0.381 & 0.149 & 0.142 & 0.230 & 0.757 & 0.129 \\
\hline SE2 & 0.307 & 0.386 & 0.398 & 0.294 & 0.347 & 0.421 & 0.201 & 0.198 & 0.317 & 0.780 & 0.220 \\
\hline SE3 & 0.263 & 0.365 & 0.291 & 0.251 & 0.354 & 0.414 & 0.136 & 0.168 & 0.329 & 0.805 & 0.192 \\
\hline TS1 & 0.314 & 0.340 & 0.277 & 0.375 & 0.287 & 0.356 & 0.137 & 0.234 & 0.418 & 0.249 & 0.746 \\
\hline $\mathrm{TS} 2$ & 0.273 & 0.275 & 0.293 & 0.387 & 0.239 & 0.339 & 0.183 & 0.303 & 0.390 & 0.159 & 0.865 \\
\hline TS3 & 0.250 & 0.299 & 0.293 & 0.423 & 0.315 & 0.378 & 0.176 & 0.312 & 0.391 & 0.151 & 0.854 \\
\hline TS4 & 0.307 & 0.358 & 0.293 & 0.481 & 0.299 & 0.460 & 0.195 & 0.371 & 0.466 & 0.207 & 0.852 \\
\hline
\end{tabular}

${ }^{1}$ The loadings of each item are in bold font. $\mathrm{CB}=$ content behavior; $\mathrm{EX}=$ purchase experience; $\mathrm{IB}=$ interactive behavior; IQ = information quality; $\mathrm{LO}=$ loyalty; $\mathrm{PR}=$ presence; $\mathrm{RE}=$ reputation; $\mathrm{SE}=$ WeChat e-commerce self-efficacy; $\mathrm{TD}=$ trust disposition; $\mathrm{TR}=$ trust; $\mathrm{TS}=$ tie strength 
Table 4. Fornell-Larcker criterion analysis and heterotrait-monotrait (HTMT) ratios. ${ }^{1}$

\begin{tabular}{|c|c|c|c|c|c|c|c|c|c|c|c|}
\hline & CB & IB & IQ & PR & TR & LO & TD & EX & RE & SE & TS \\
\hline CB & 0.721 & & & & & & & & & & \\
\hline IB & $\begin{array}{l}0.415 \\
(0.717)\end{array}$ & 0.741 & & & & & & & & & \\
\hline IQ & $\begin{array}{l}0.361 \\
(0.618)\end{array}$ & $\begin{array}{l}0.506 \\
(0.821)\end{array}$ & 0.759 & & & & & & & & \\
\hline PR & $\begin{array}{l}0.459 \\
(0.704)\end{array}$ & $\begin{array}{l}0.474 \\
(0.692)\end{array}$ & $\begin{array}{l}0.391 \\
(0.573)\end{array}$ & 0.724 & & & & & & & \\
\hline TR & $\begin{array}{l}0.362 \\
(0.576)\end{array}$ & $\begin{array}{l}0.524 \\
(0.802)\end{array}$ & $\begin{array}{l}0.579 \\
(0.845)\end{array}$ & $\begin{array}{l}0.444 \\
(0.601)\end{array}$ & 0.797 & & & & & & \\
\hline LO & $\begin{array}{l}0.376 \\
(0.583)\end{array}$ & $\begin{array}{l}0.530 \\
(0.792)\end{array}$ & $\begin{array}{l}0.558 \\
(0.817)\end{array}$ & $\begin{array}{l}0.488 \\
(0.638)\end{array}$ & $\begin{array}{l}0.639 \\
(0.868)\end{array}$ & 0.758 & & & & & \\
\hline TD & $\begin{array}{l}0.243 \\
(0.352)\end{array}$ & $\begin{array}{l}0.169 \\
(0.224)\end{array}$ & $\begin{array}{l}0.291 \\
(0.397)\end{array}$ & $\begin{array}{l}0.292 \\
(0.363)\end{array}$ & $\begin{array}{l}0.274 \\
(0.340)\end{array}$ & $\begin{array}{l}0.297 \\
(0.360)\end{array}$ & 0.811 & & & & \\
\hline EX & $\begin{array}{l}0.203 \\
(0.271)\end{array}$ & $\begin{array}{l}0.338 \\
(0.436)\end{array}$ & $\begin{array}{l}0.358 \\
(0.456)\end{array}$ & $\begin{array}{l}0.303 \\
(0.336)\end{array}$ & $\begin{array}{l}0.323 \\
(0.383)\end{array}$ & $\begin{array}{l}0.420 \\
(0.483)\end{array}$ & $\begin{array}{l}0.095 \\
(0.102)\end{array}$ & 1.000 & & & \\
\hline RE & $\begin{array}{l}0.367 \\
(0.567)\end{array}$ & $\begin{array}{l}0.435 \\
(0.636)\end{array}$ & $\begin{array}{l}0.443 \\
(0.624)\end{array}$ & $\begin{array}{l}0.455 \\
(0.587)\end{array}$ & $\begin{array}{l}0.543 \\
(0.710)\end{array}$ & $\begin{array}{l}0.562 \\
(0.724)\end{array}$ & $\begin{array}{l}0.208 \\
(0.246)\end{array}$ & $\begin{array}{l}0.366 \\
(0.412)\end{array}$ & 0.780 & & \\
\hline SE & $\begin{array}{l}0.363 \\
(0.595)\end{array}$ & $\begin{array}{l}0.446 \\
(0.704)\end{array}$ & $\begin{array}{l}0.437 \\
(0.683)\end{array}$ & $\begin{array}{l}0.329 \\
(0.464)\end{array}$ & $\begin{array}{l}0.457 \\
(0.654)\end{array}$ & $\begin{array}{l}0.519 \\
(0.724)\end{array}$ & $\begin{array}{l}0.207 \\
(0.262)\end{array}$ & $\begin{array}{l}0.217 \\
(0.263)\end{array}$ & $\begin{array}{l}0.375 \\
(0.509)\end{array}$ & 0.781 & \\
\hline TS & $\begin{array}{l}0.345 \\
(0.499)\end{array}$ & $\begin{array}{l}0.386 \\
(0.536)\end{array}$ & $\begin{array}{l}0.349 \\
(0.488)\end{array}$ & $\begin{array}{l}0.507 \\
(0.620)\end{array}$ & $\begin{array}{l}0.346 \\
(0.439)\end{array}$ & $\begin{array}{l}0.467 \\
(0.579)\end{array}$ & $\begin{array}{l}0.209 \\
(0.238)\end{array}$ & $\begin{array}{l}0.372 \\
(0.399)\end{array}$ & $\begin{array}{l}0.505 \\
(0.623)\end{array}$ & $\begin{array}{l}0.232 \\
(0.303)\end{array}$ & 0.830 \\
\hline
\end{tabular}

${ }^{1}$ HTMT ratios are in the parentheses. The diagonal element, which shows the square root of AVE on each construct, is in bold font. $\mathrm{CB}=$ content behavior; $\mathrm{EX}=$ purchase experience; $\mathrm{IB}=$ interactive behavior; $\mathrm{IQ}=$ information quality; $\mathrm{LO}=$ loyalty; $\mathrm{PR}=$ presence; $\mathrm{RE}=$ reputation; $\mathrm{SE}=$ WeChat e-commerce self-efficacy; $\mathrm{TD}=$ trust disposition; $\mathrm{TR}=$ trust; $\mathrm{TS}=$ tie strength.

\subsection{Common method bias}

Common method bias (CMB) resulting from multiple sources such as consistency motif and social desirability (Podsakoff et al., 2003), which may have a serious impact on the results of data analysis. For all self-reported data, there is a potential for CMB. To reduce this bias, we first ensured that all respondents understood the survey's confidentiality and all the questions. Then we conducted Harman's one factor test. The exploratory factor analysis results show that the common factor explains $27.69 \%(<50 \%)$ of the variance in the model, indicating that CMB is acceptable. Besides, following the suggestions of Podsakoff et al. (2003) and Liang et al. (2007), this study added a common method factor to the PLS-SEM model. The index includes all the indicators of the principal component construct. The construct and this method make substantial calculations on the variance of each indicator. The test results show that the average substantial variation of each index is 0.611 , the average common method variation is 0.013 , and the ratio of the two is $47: 1$. And most of the method factor loads are not significant. Given the insignificant and small degree of method variation, it can be considered that the problem of CMB in this study is not serious.

\subsection{Structural model analysis}

Following Ringle et al.'s (2012) and Hair et al.'s (2020) guidelines, this study evaluated the structural model by the following criteria: (1) model fit (standardized root mean square residual (SRMR)); (2) collinearity assessment among the constructs (variance inflation factor (VIF)); (3) structural model path coefficients; (4) coefficient of determination $\left(\mathrm{R}^{2}\right)$; and (5) predictive relevance (Stone-Geisser $\mathrm{Q}^{2}$ ). 
First, the SRMR is currently the only approximate model fit criterion implemented for PLS path modeling (Henseler et al., 2016), and the cut-off value is 0.08 proposed by Hu and Bentler (1999). In this study, the SRMR is $0.062(<0.08)$, indicating a good fit for the overall model.

Second, the VIF values for each construct are between 1.000 and 2.464. All the VIF values are much smaller than the threshold of 10 recommended by Gefen et al. (2011), indicating that the collinearity among the predictor constructs is not an issue.

Third, to examine the size and significance of the path coefficients, this research conducted a resampling bootstrap procedure to repeatedly 672 samples 5,000 times (Hair et al., 2013). Bootstrapping is a nonparametric significance test, which is widely applied in PLS-SEM because PLS-SEM mainly adopted to test non-normal data (Latan and Noonan, 2017). This process can test the hypothesized relationships among the constructs. For the path coefficient values, the closer they are to 0 , the weaker they are in predicting dependent (endogenous) constructs, and the closer they are to the absolute value of 1, the stronger their predictive power is. However, bootstrapping with non-normal data may produce peaked and skewed bootstrap distributions. To minimizes this problem to some degree, this study used the Bias-Corrected and Accelerated (BCa) bootstrapping routine, because it adjusts the confidence intervals for skewness (Hair et al., 2017).

Table 5 presents the main results and all hypotheses are statistically significant. Specifically, content behavior positively influences information quality $(\beta=0.182, P<0.001$, H1a), and interactive behavior also positively influences information quality $(\beta=0.431, P<0.001, \mathrm{H} 1 \mathrm{~b})$. That is, the higher the quality of the content behavior or interactive behavior of WeChat food marketers, the easier it is for consumers to perceive higher information quality. Similarly, content behavior positively affects presence $(\beta=0.316, P<0.001, \mathrm{H} 2 \mathrm{a})$, and interactive behavior also positively affects presence $(\beta=0.343, P<0.001, \mathrm{H} 2 \mathrm{~b})$. That is, when consumers have a higher evaluation of marketers' content behavior or interactive behavior, consumers perceive a higher presence. Information quality positively affects trust $(\beta=0.317, P<0.001, \mathrm{H} 3)$, and presence also positively affects trust $(\beta=0.131, P<0.001, \mathrm{H} 4)$. That is, when consumers perceive higher information quality or higher presence in the process of WeChat engagement, consumers have higher trust in food marketers. And trust increases loyalty $(\beta=0.347, P<0.001, \mathrm{H} 7)$. That is, the more consumers trust food marketers, the more loyal they are to food marketers.

Moreover, this procedure also did the mediation analysis. As shown in Table 5, the indirect effects (content behavior $\rightarrow$ trust, interactive behavior $\rightarrow$ trust) were both significant at 0.001 level, which suggests that information quality and/or presence play mediating roles in the relationship between WeChat marketing behavior and trust. Specifically, the information quality positively mediates the influence of content behavior $(\beta=0.058, P<0.001)$ and interactive behavior $(\beta=0.136, P<0.001)$ on trust, presence also positively mediates the influence of content behavior $(\beta=0.041, P<0.001)$ and interactive behavior $(\beta=0.045, P<0.001)$ on trust has been verified, hypothesis $\mathrm{H} 5$ and $\mathrm{H} 6$ have been verified. That is, WeChat behavior (content behavior and interactive behavior) of food marketers has two influence mechanisms on consumer trust. First, WeChat marketing behavior improves consumer perception of information quality and then enhances consumer trust. Second, WeChat marketing behavior enhances consumer sense of presence and then enhances consumer trust. Furthermore, the coefficient of interactive behavior is higher than the coefficient of content behavior, indicating that interactive behavior makes more contribution to the explanation of consumer trust.

Fourth, $\mathrm{R}^{2}$ values are widely used for measuring the structural model's predictive power in PLS-SEM. The results show that the $\mathrm{R}^{2}$ coefficients of loyalty ( 0.565$)$, trust ( 0.480$)$, information quality $(0.284)$, and presence (0.308) are all larger than the cut-off value of 0.1 (Falk and Miller, 1992). It indicates an adequate explanatory power of the structural model.

Fifth, the results show that Stone-Geisser $Q^{2}$ (=1-SSE/SSO) values for trust (0.294), loyalty (0.315), information quality $(0.157)$, and presence $(0.158)$ are all above 0 . This test provides support for the model's predictive relevance regarding the reflective endogenous latent variables (Hair et al., 2013). 
Table 5. Structure model results. ${ }^{1,2}$

\begin{tabular}{|c|c|c|c|}
\hline Hypotheses & Path coefficient & STD & $95 \%$ confidence interval \\
\hline \multicolumn{4}{|l|}{ Direct effects } \\
\hline H1a: CB $\rightarrow$ IQ & $0.182 * * *$ & 0.037 & $(0.111,0.255)$ \\
\hline H1b: IB $\rightarrow$ IQ & $0.431 * * *$ & 0.037 & $(0.357,0.503)$ \\
\hline $\mathrm{H} 2 \mathrm{a}: \mathrm{CB} \rightarrow \mathrm{PR}$ & $0.316^{* * *}$ & 0.044 & $(0.234,0.405)$ \\
\hline H2b: IB $\rightarrow$ PR & $0.343 * * *$ & 0.041 & $(0.261,0.421)$ \\
\hline H3: IQ $\rightarrow$ TR & $0.317 * * *$ & 0.038 & $(0.239,0.388)$ \\
\hline $\mathrm{H} 4: \mathrm{PR} \rightarrow \mathrm{TR}$ & $0.131 * * *$ & 0.034 & $(0.063,0.198)$ \\
\hline H7: TR $\rightarrow$ LO & $0.347 * * *$ & 0.038 & $(0.273,0.421)$ \\
\hline $\mathrm{TD} \rightarrow \mathrm{TR}$ & 0.056 & 0.032 & $(-0.004,0.124)$ \\
\hline $\mathrm{EX} \rightarrow \mathrm{TR}$ & 0.042 & 0.036 & $(-0.027,0.112)$ \\
\hline $\mathrm{EX} \rightarrow \mathrm{LO}$ & $0.140 * * *$ & 0.031 & $(0.080,0.201)$ \\
\hline $\mathrm{RE} \rightarrow \mathrm{TR}$ & $0.273 * * *$ & 0.043 & $(0.188,0.357)$ \\
\hline $\mathrm{RE} \rightarrow \mathrm{LO}$ & $0.151 * * *$ & 0.039 & $(0.074,0.227)$ \\
\hline $\mathrm{SE} \rightarrow \mathrm{TR}$ & $0.160 * * *$ & 0.040 & $(0.082,0.241)$ \\
\hline $\mathrm{SE} \rightarrow \mathrm{LO}$ & $0.235^{* * *}$ & 0.037 & $(0.163,0.309)$ \\
\hline $\mathrm{TS} \rightarrow \mathrm{TR}$ & -0.033 & 0.039 & $(-0.109,0.045)$ \\
\hline $\mathrm{TS} \rightarrow \mathrm{LO}$ & $0.164 * * *$ & 0.034 & $(0.098,0.229)$ \\
\hline \multicolumn{4}{|l|}{ Indirect effects } \\
\hline Total indirect effects: $\mathrm{CB} \rightarrow \mathrm{TR}$ & $0.099 * * * \mathrm{a}$ & 0.018 & $(0.065,0.135)$ \\
\hline $\mathrm{H} 5 \mathrm{a}: \mathrm{CB} \rightarrow \mathrm{IQ} \rightarrow \mathrm{TR}$ & $0.058 * * *$ & 0.013 & $(0.034,0.084)$ \\
\hline H6a: $\mathrm{CB} \rightarrow \mathrm{PR} \rightarrow \mathrm{TR}$ & $0.041 * * *$ & 0.012 & $(0.019,0.069)$ \\
\hline Total indirect effects: IB $\rightarrow$ TR & $0.181 * * * b$ & 0.023 & $(0.136,0.228)$ \\
\hline H5b: IB $\rightarrow$ IQ $\rightarrow$ TR & $0.136 * * *$ & 0.021 & $(0.097,0.178)$ \\
\hline H6b: $\mathrm{IB} \rightarrow \mathrm{PR} \rightarrow \mathrm{TR}$ & $0.045 * * *$ & 0.013 & $(0.021,0.071)$ \\
\hline
\end{tabular}

$1 * * * P<0.001 ; * * P<0.01 ; * P<0.05$. $^{\text {a }}$ The coefficient of total indirect effects of content behavior on trust is equally to the coefficient values of H6a (0.058) plus the coefficient values of $\mathrm{H} 7 \mathrm{a}(0.041){ }^{\mathrm{b}}$ The coefficient of total indirect effects of interactive behavior on trust is equally to the coefficient values of $\mathrm{H} 6 \mathrm{~b}(0.136)$ plus the coefficient values of $\mathrm{H} 7 \mathrm{~b}(0.045)$.

${ }^{2} \mathrm{CB}=$ content behavior; $\mathrm{EX}=$ purchase experience; $\mathrm{IB}=$ interactive behavior; $\mathrm{IQ}=$ information quality; $\mathrm{LO}=$ loyalty; $\mathrm{PR}=$ presence; $\mathrm{RE}=$ reputation; $\mathrm{SE}=$ WeChat e-commerce self-efficacy; $\mathrm{TD}=$ trust disposition; $\mathrm{TR}=$ trust; $\mathrm{TS}=$ tie strength .

\subsection{Robustness checks}

The robustness check of the PLS-SEM results includes OLS regression analysis, assessment of unobserved heterogeneity, and endogeneity. First, this study did OLS regression with constructs are reflected by the mean of corresponding measured variables. The OLS regression results are consistent with the structural equation model results, indicating that the research results are robust. Second, this paper conducted a multi-group analysis (MGA) to consider the unobserved heterogeneity (Becker et al., 2013). The MGA results show that most of the paths (H1-H7) are not significantly heterogeneous in demographic characteristics. Therefore, the interference of demographic characteristics on the main paths of the research model can be ignored. Third, this study applied the Gaussian copula approach to deal with endogeneity (Hult et al., 2018). By applying this approach, we exclude the endogenous problem of information quality and trust and identified a potential endogeneity issue of presence. However, we could not explain the problem in terms of the instrumental variable. Therefore, we still use the result of PLS-SEM. Please see specific robustness checks in Appendix S4 of the Supplementary Material. 


\section{Discussion}

\subsection{Discussion of key findings}

This study has three notable findings. First, online marketing behaviors can enhance consumer trust. Consistent with Tan and Chen's (2018) findings, this study acknowledged and highlighted the importance of the seller's marketing behavior in trust building. Moreover, the results show that interactive behavior has a greater effect on consumer trust compared with content behavior. A possible explanation is that online food marketplaces (e.g. WeChat marketplaces) provide convenient communication chances for sellers and consumers. Consumer motivations to engage in online marketplaces appear to have a stronger social basis (Chen et al., 2020). They may spend more time on interactive activities on online platforms, so that they may receive more influence from interactive behavior. Also, compared with content behavior, interactive behavior can deal with consumer problems timely and effectively, which can favor greater consumer satisfaction. Therefore, interactive behavior makes more contribution to consumer trust.

Second, both information quality and presence positively mediate the effect of WeChat marketing behavior on consumer trust. We demonstrated the information mechanism of trust building based on signaling theory (Yue et al., 2017). Furthermore, we provide new insights into understanding consumer food trust building online by applying presence theory and demonstrating that presence can interpret consumer trust in online food marketplaces. However, we have not identified the institutional-based antecedents of trust in this study. The main reason maybe like this: WeChat commerce is a new form of e-commerce that has gained rapid development in recent years, and its regulatory system is not sound at present. Therefore, WeChat food transactions may have high risks for consumers so that consumers may mainly rely on information and relationships to decide whether to trust the seller and products.

Third, this study empirically shows that consumer trust is a predictor of loyalty in the online food economy, which is consistent with the prior research in general online marketplaces (Ou et al., 2014). A possible reason is that trust favors greater satisfaction and then enhance loyalty (Herrera and Blanco, 2011). This finding emphasizes the key contribution of trust in business success because loyalty can lead to high levels of purchase behavior (Lee and Goudeau, 2014).

\subsection{Implications}

This study makes several theoretical contributions. First, it highlighted the influence of food seller's WeChat marketing behavior on consumer trust, which addresses the paucity of online food trust building and provides references for future scholars to further study the online food business. Second, it comprehensively analyzes the impact of two types of WeChat marketing behaviors on consumer trust. This study proposed another classification of WeChat marketing behavior (content behavior and interactive behavior) compared with Chen and Tan's (2019) study. And then it discussed not only content behavior noted by prior studies but also interactive behavior and proved both are key contributes to consumer trust in online food marketplaces. This is useful for researchers to investigate more characteristics of WeChat marketing and their effects on consumer behavior. Third, this study not only highlights the informational mechanisms of trust building but also introduces the presence theory to explain trust building. This work provides a reference for researchers to focus on presence theory and further explore other mechanisms of trust building in online food marketplaces.

From a practical perspective, this study guides for food sellers to build consumer trust in WeChat food marketplaces. Given that this study demonstrates the influence mechanisms of WeChat marketing on trust, food sellers should actively carry out WeChat marketing behaviors and aim to improve consumers' perceived information quality and presence. For example, when performing WeChat content behaviors, WeChat marketers could provide real, reliable, and helpful content information to consumers, and strengthen the richness of content presentation forms. Moreover, when performing WeChat interactive behaviors, WeChat marketers could respond to consumers' WeChat messages timely and effectively as much as possible, so 
that they can effectively improve consumers' perceived information quality and presence, and subsequently promote consumer trust.

\subsection{Limitations and future research}

This study still has some limitations. First is the data limitations. This article relies on survey-based data, in which independent variables cannot be exogenously manipulated. Limited by current data, this study cannot find suitable instrumental variables to deal with possible endogenous issues effectively. Future research could undertake experiments to obtain consumer data. Researchers can also collect qualitative data to strengthen the explanatory power of quantitative results. Second, the theoretical perspective of building consumer trust may not be limited to signaling theory and presence theory, future studies could further explore in other theoretical directions, such as media synchronization theory. Third, this article focuses on the mediating mechanism of trust building in online food marketplaces, neglecting the discussion about the boundary conditions of the mediating mechanism. Therefore, in the future, researchers can explore what is the moderating mechanism for establishing and maintaining consumer trust in the WeChat marketing environment.

\section{Conclusions}

How to build consumer trust is of great significance to the marketing success of online food marketers. Drawing on signaling theory and presence theory, this study investigates the influence mechanism of WeChat food seller's marketing behavior on consumer trust. This study shows that food seller's WeChat marketing behavior (content behavior and interactive behavior) positively affects consumer trust through the mediating effect of consumer's perceived information quality and presence. And consumer trust can enhance consumer loyalty. Although there are still some limitations, this study does make several theoretical and practical contributions.

\section{Supplementary material}

Supplementary material can be found online at https://doi.org/10.22434/IFAMR2020.0159

Appendix S1. Partial least squares structural equation modeling equations.

Appendix S2. Measures.

Appendix S3. Supplementary figures and tables.

Appendix S4. Robustness checks.

\section{Acknowledgements, financial support and conflict of interest}

This study was funded by Chinese National Natural Science Foundation grants (No. 71773138, No. 72073136 and No. 71633005) and the Beijing Technology and Business University Young Teachers Scientific Research Starting Fund (No. QNJJ2021-45). The interpretations, conclusions, and recommendations, however, are the authors' and do not necessarily represent the positions of the institution. No conflict of interest exists in the submission of this manuscript, and the manuscript is approved by all authors for publication.

\section{References}

Bapna, R., A. Gupta, S. Rice and A. Sundararajan. 2017. Trust and the strength of ties in online social networks: an exploratory field experiment. MIS Quarterly 41(1): 115-130.

Becker, J.M., A. Rai, C.M. Ringle and F. Völckner. 2013. Discovering unobserved heterogeneity in structural equation models to avert validity threats. MIS Quarterly 37(3): 665-694.

Beldad, A., M.D. Jong and M. Steehouder. 2010. How shall I trust the faceless and the intangible? A literature review on the antecedents of online trust. Computers in Human Behavior 26(5): 857-869. 
Casalo, L., C. Flavian and M. Guinaliu. 2008. The role of perceived usability, reputation, satisfaction and consumer familiarity on the website loyalty formation process. Computers in Human Behavior 24(2): 325-345.

Chen, J., S. Huang and Y. Liu. 2020. Operations management in the digitalization era: from empowering to enabling. Journal of Management World 2: 117-128.

Chen, S.C., C. Raab and S. Tanford. 2015. Antecedents of mandatory customer participation in service encounters: an empirical study. International Journal of Hospitality Management 46: 65-75.

Chen, W. 2013. The effects of different types of trust on consumer perceptions of food safety. China Agricultural Economic Review 5(1): 43-65.

Chen, W. and S. Tan. 2019. Impact of social media apps on producer-member relations in China's community supported agriculture. Canadian Journal of Development Studies 40(1): 97-112.

Chin, W.W. 1998. The partial least squares to structural equation modeling. In: G.A. Marcoulides (ed.) Modern methods for business research. Erlbaum, Mahwah, NJ, USA, pp. 295-358.

Connelly, B.L., S.T. Certo, R.D. Ireland and C.R. Reutzel. 2011. Signaling theory: a review and assessment. Journal of Management 37(1): 39-67.

De Jonge, J., J.C.M. Van Trijp, I.A. Van der Lans, R.J. Renes and L.J. Frewer. 2008. How trust in institutions and organizations builds general consumer confidence in the safety of food: a decomposition of effects. Appetite 51(2): 311-317.

Falk, R.F. and N.B. Miller. 1992. A primer for softmodelling. University of Akron Press, Akron, OH, USA.

Fan, J., W. Zhou, X. Yang, B. Li and Y. Xiang. 2019. Impact of social support and presence on swift guanxi and trust in social commerce. Industrial Management \& Data Systems 119(9): 2033-2054.

Fornell, C. and D.F. Larcker. 1981. Evaluating structural equation models with unobservable variables and measurement error. Journal of Marketing Research 18(1): 39-50.

Gefen, D. and D.W. Straub. 2004. Consumer trust in B2C e-commerce and the importance of social presence: experiments in e-products and e-services. Omega - International Journal of Management Science 32(6): 407-424.

Gefen, D., E. Karahanna and D.W. Straub. 2003. Trust and TAM in online shopping: an integrated model. MIS Quarterly 27(1): 51-90.

Gefen, D., E.E. Rigdon and D.W. Straub. 2011. An update and extension to SEM guidelines for administrative and social science research. Editorial comment. MIS Quarterly 35(2): 3-14.

Hair, J.F., G.T.M. Hult, C. Ringle and M. Sarstedt. 2013. A primer on partial least squares structural equation modeling (PLS-SEM). SAGE Publications, Thousand Oaks, CA, USA.

Hair, J.F., J.J. Risher, M. Sarstedt and C.M. Ringle. 2017. When to use and how to report the results of PLSSEM. European Business Review 31(1): 2-24. https://doi.org/10.1108/EBR-11-2018-0203

Hair, J.F., M.C. Howard and C. Nitzl. 2020. Assessing measurement model quality in PLS-SEM using confirmatory composite analysis. Journal of Business Research 109: 101-110.

Hajli, N., J. Sims, A.H. Zadeh and M.O. Richard. 2017. A social commerce investigation of the role of trust in a social networking site on purchase intentions. Journal of Business Research 71: 133-141.

Henseler, J., C.M. Ringle and M. Sarstedt. 2015. A new criterion for assessing discriminant validity in variancebased structural equation modeling. Journal of the Academy of Marketing Science 43(1): 115-135.

Henseler, J., C.M. Ringle and R.R. Sinkovics. 2009. The use of partial least squares path modeling in international marketing. Social Science Electronic Publishing 20(4): 277-319.

Henseler, J., G. Hubona, and P. Ray. 2016. Using PLS path modeling in new technology research: updated guidelines. Industrial Management \& Data Systems 116(1): 2-20.

Herrera, C.F. and C.F. Blanco. 2011. Consequences of consumer trust in PDO food products: the role of familiarity. Journal of Product \& Brand Management 20(4): 282-296.

Hinton, P.R., C. Brownlow, I. McMurray and B. Cozens. 2004. SPSS explained. Routledge, London, UK.

Hu, L.-T. and P.M. Bentler. 1999. Cutoff criteria for fit indexes in covariance structure analysis: conventional criteria versus new alternatives. Structural Equation Modeling 6(1): 1-55.

Hult, G.T.M., F. Hair, D. Proksch, M. Sarstedt and C.M. Ringle. 2018. Addressing endogeneity in international marketing applications of partial least squares structural equation modeling. Journal of International Marketing 26(3): 1-21. 
Kandampully, J., T.C. Zhang and A. Bilgihan. 2015. Customer loyalty: a review and future directions with a special focus on the hospitality industry. International Journal of Contemporary Hospitality Management 27(3): 379-414.

Kim, S. and H. Park. 2013. Effects of various characteristics of social commerce (s-commerce) on consumers' trust and trust performance. International Journal of Information Management 33(2): 318-332.

Kim, Y. and R.A. Peterson. 2017. A meta-analysis of online trust relationships in e-commerce. Journal of Interactive Marketing 38: 44-54.

Kozlenkova, I.V., R.W. Palmatier, E. Fang, B. Xiao and M. Huang. 2017. Online relationship formation. Journal of Marketing 81: 21-40.

Latan, H. and R. Noonan. 2017. Partial least squares path modeling: Basic concepts, methodological issues and applications. Springer International Publishing AG, Cham, Switzerland.

Lee, H. and C. Goudeau. 2014. Consumers' beliefs, attitudes, and loyalty in purchasing organic foods. British Food Journal 116(6): 918-930.

Lees, N., P. Nuthall and M.M.J. Wilson. 2020. Relationship quality and supplier performance in food supply chains. International Food and Agribusiness Management Review 23(3): 425-445.

Liang, H., N. Saraf, Q. Hu and Y. Xue. 2007. Assimilation of enterprise systems: the effect of institutional pressures and the mediating role of top management. MIS Quarterly 31(1): 59-87.

Liao, C., P. Palvia and H. Lin. 2006. The roles of habit and web site quality in e-commerce. International Journal of Information Management 26(6): 469-483.

Lu, B., Q. Zeng and W. Fan. 2016. Examining macro-sources of institution-based trust in social commerce marketplaces: an empirical study. Electronic Commerce Research and Applications 20: 116-131.

Ministry of Commerce of the People's Republic of China. 2020. E-commerce in China 2019. Ministry of Commerce, Beijing, China. Available at: https://dzswgf.mofcom.gov.cn/news_attachments/ b5aef3b5264e36264ee4268a7426db6183c8c16b.pdf (in Chinese)

Oghazi, P., S. Karlsson, D. Hellstrom and K. Hjort. 2018. Online purchase return policy leniency and purchase decision: mediating role of consumer trust. Journal of Retailing and Consumer Services 41: 190-200.

Ou, C.X., P.A. Pavlou and R.M. Davison. 2014. Swift guanxi in online marketplaces: the role of computermediated communication technologies. MIS Quarterly 38(1): 209-230.

Park, E., K.J. Kim and S.J. Kwon. 2017. Corporate social responsibility as a determinant of consumer loyalty: an examination of ethical standard, satisfaction, and trust. Journal of Business Research 76: 8-13.

Pentina, I., L. Zhang and O. Basmanova. 2013. Antecedents and consequences of trust in a social media brand: a cross-cultural study of Twitter. Computers in Human Behavior 29(4): 1546-1555.

Podsakoff, P.M., S.B. Mackenzie, J.Y. Lee and N.P. Podsakoff. 2003. Common method biases in behavioral research: a critical review of the literature and recommended remedies. Journal of Applied Psychology 88(5): 879-903.

Poppe, C. and U. Kjærnes. 2003. Trust in food in Europe: a comparative analysis. SIFO Report No. 5-2003. National Institute for Consumer Research, Oslo, Norway.

Ringle, C.M., M. Sarstedt and D.W. Straub. 2012. A critical look at the use of PLS-SEM in MIS Quarterly. MIS Quarterly 36(1): 3-14.

Shankar, V., G.L. Urban and F. Sultan. 2002. Online trust: a stakeholder perspective, concepts, implications, and future directions. Journal of Strategic Information Systems 11: 325-344.

Siegrist, M., N. Stampfli, H. Kastenholz and C. Keller. 2008. Perceived risks and perceived benefits of different nanotechnology foods and nanotechnology food packaging. Appetite 51(2): 283-290.

Sillence, E., C. Hardy, L.C. Medeiros and J.T. Lejeune. 2016. Examining trust factors in online food risk information: the case of unpasteurized or 'raw' milk. Appetite 99: 200-210.

Spence, M. 1973. Job market signaling. Quarterly Journal of Economics 87: 355-374.

Tan, S. and W. Chen. 2018. How to build consumers' trust in community supported agriculture: the case of four seasons share organic farm in Huizhou, Guangdong Province. China Agricultural University Journal of Social Sciences Edition 35(4): 103-116. (in Chinese)

Tang, J., H. Folmer and J. Xue. 2015. Technical and allocative efficiency of irrigation water use in the Guanzhong Plain, China. Food Policy 50: 43-52. 
Wallace, E., I. Buil and L. De Chernatony. 2017. Consumers' self-congruence with a 'liked' brand. European Journal of Marketing 51(2): 367-390.

Wang, Y., Q. Min and S. Han. 2016. Understanding the effects of trust and risk on individual behavior toward social media platforms. Computers in Human Behavior 56(56): 34-44.

Yue, L., Y. Liu and Q. Chen. 2017. Research of consumers' trust on quality signal of agricultural products and influencing factors in C2C mode: based on ordinal logistic model. Journal of Nanjing Agricultural University (Social Sciences Edition) 17(2): 113-122. (in Chinese)

Zahedi, F.M. and J. Song. 2008. Dynamics of trust revision: using health infomediaries. Journal of Management Information Systems 24(4): 225-248.

Zhang, J.Z., G.F. Watson, R.W. Palmatier and R.P. Dant. 2016. Dynamic relationship marketing. Journal of Marketing 80(5): 53-75.

Zhou, T. 2012. Understanding users' initial trust in mobile banking: an elaboration likelihood perspective. Computers in Human Behavior 28: 1518-1525. 